\title{
Application of distributed fiber optic sensing technique in land subsidence monitoring in coastal areas: a case study in Tianjin, China
}

\author{
Su-Ping Liu ${ }^{1,2}$, Bin Shi ${ }^{1}$, Kai Gu ${ }^{1}$, Cheng-Cheng Zhang ${ }^{1}$, Song Zhang ${ }^{1}$, Peng Yang ${ }^{1}$, and Ji-Long Yang \\ ${ }^{1}$ School of Earth Sciences and Engineering, Nanjing University, Nanjing, 210023, China \\ ${ }^{2}$ School of Civil Engineering, University of Leeds, Leeds, LS2 9JT, UK \\ ${ }^{3}$ Tianjin Center, China Geological Survey, Tianjin, 300170, China
}

Correspondence: Bin Shi (shibin@nju.edu.cn) and Kai Gu (gukai@nju.edu.cn)

Published: 22 April 2020

\begin{abstract}
Land subsidence is a worldwide geohazard caused by various factors, and its direct impact is loss of elevation, which is especially severe in coastal areas due to sea level rise. Quantifying contributions of compressed strata is significant for evaluating the subsidence. In this paper, we used distributed fiber optic sensing (DFOS) with Brillouin scattering to monitor the strain distribution along optical cables embedded in a borehole located in Tianjin, China. The novel technique revealed that the land subsidence rate was $21.2 \mathrm{~mm} \mathrm{a}^{-1}$ from 2017 to 2019. The strata contributed to the subsidence have been identified in the range of 3 to $35 \mathrm{~m}$. The results showed good agreement with those obtained by a group of extensometers. We demonstrated that DFOS could be a supplement to land subsidence monitoring technologies in coastal areas.
\end{abstract}

\section{Introduction}

Land subsidence refers to the decline of ground surface elevation, which can be attributed to anthropogenic and natural reasons (Xue et al., 2005). In coastal areas, land subsidence has become one of the most serious geological hazards because of multi-layer coastal soft soils, groundwater pumping, and excessive constructions. The situation is getting worse by the joint-influence of sea level rise. Therefore, it is significant to adopt robust technologies for land subsidence monitoring in coastal areas. Methods commonly adopted to perform surveys and research in land subsidence monitoring mainly include GPS, InSAR, and leveling and extensometers (Baldi et al., 2009; Amelung et al., 1999; Erkens et al., 2015; Galloway et al., 2016). GPS, InSAR, and leveling monitor ground motion, so it is difficult to identify the depth and contributions of compressed strata. Extensometers need a group of monitoring positions to measure deformation in specific strata, and the measured deformation is spatially limited.

The distributed fiber optic sensing (DFOS) technique overcomes the above shortcomings, and it has advantages of long-distance and continuous monitoring along a single optical fiber (OF). Researchers have successfully adopted DFOS technique in land subsidence monitoring in Suzhou, the Yangtze River Delta in China (Wu et al., 2015; Gu et al., 2018; Zhang et al., 2018).

Can DFOS be used in coastal areas? Tianjin is a coastal city in China, which has been suffering from severe subsidence (Shearer, 1998; Yi et al., 2011; Yang et al., 2019). In this paper, we implemented DFOS technique to build a fullsection monitoring system in Tianjin from September 2017 to May 2019. The dominant strata compression in Tianjin were identified, and the results of DFOS were verified by extensometers.

\section{Methodology and in-situ boreholes}

\subsection{DFOS technology}

Most DFOS technologies are based on Brillouin scatting, including BOTDA, BOTDR, and BOFDA. The Brillouin frequency shift (BFS) has a linear correlation to the changes in longitudinal strain and temperature along OF. In this study, 
we used the BOTDR technology, of which the measuring principle is as follows (Ohno et al., 2001):

$v_{\mathrm{B}}(\varepsilon, T)=v_{\mathrm{B}}\left(0, T_{0}\right)+\frac{\partial v_{\mathrm{B}}(\varepsilon)}{\partial \varepsilon} \varepsilon+\frac{\partial v_{\mathrm{B}}(T)}{\partial T}\left(T-T_{0}\right)$

where $v_{\mathrm{B}}(\varepsilon, T)$ is the BFS; $T$ is the temperature; $\varepsilon$ is the strain; $v_{\mathrm{B}}\left(0, T_{0}\right)$ is the BFS while the temperature is $T_{0}$ (initial temperature) and the strain is 0 (no strain); $\frac{\partial v_{\mathrm{B}}(\varepsilon)}{\partial \varepsilon}$ and $\frac{\partial v_{\mathrm{B}}(T)}{\partial T}$ mean the strain and temperature coefficient of $\mathrm{OF}$, respectively.

\subsection{DFOS system (G06)}

In order to monitor the strata deformation at different depths, we drilled a $100 \mathrm{~m}$ depth borehole (G06, Fig. 1a and b) and embedded optical fiber sensors in the borehole in September $2017\left(39^{\circ} 03^{\prime} 56^{\prime \prime} \mathrm{N}, 117^{\circ} 37^{\prime} 36^{\prime \prime} \mathrm{E}\right)$. The optical fiber sensors are $5 \mathrm{~m}$-fixed-point cable (5-FPC) produced by Suzhou NanZee Sensing Ltd, China. The BOTDR interrogator used in this study is AV6419 Optical Fiber Temperature/Strain Analyzer produced by the 41st Research Institute of China Electronics Technology Group Corporation, China. Its minimum spatial resolution is $1 \mathrm{~m}$, the readout resolution accuracy is $10 \mathrm{~cm}$ and the strain measurement accuracy is about $\pm 40 \mu \varepsilon$ in the study. Material, mechanical properties of the cable, and installation steps can be found in our previous research (Wu et al., 2015; Gu et al., 2018). The initial data of DFOS monitoring system were collected on 30 September 2017, and the monitoring was carried out in the next two years until 30 May 2019 (Fig. 1c). The cable strain was monitored by AV6419 while the displacement can be calculated by Eq. (2):

$\Delta L=\int_{l_{2}}^{l_{1}} \varepsilon(l) d l$

where $\Delta L$ is the deformation from $l_{1}$ to $l_{2}, \varepsilon(l)$ is the strain along the cable.

\subsection{Extensometer (G02)}

According to the historical data, the elevation of the most serious area reduced by $3.2-3.4 \mathrm{~m}$ from 1959 to 2008, and the evaluations of some regions are lower than the sea level (Hu et al., 2009). There is a group of extensometers (G02) with a maximum borehole depth of $1218 \mathrm{~m}$ in the study site (Yang et al., 2019). In the study, DFOS results were verified by the results of four extensometers at depths of $3 \mathrm{~m}$ (F0), $33 \mathrm{~m}$ (F1), $60 \mathrm{~m}$ (F2), and $95.5 \mathrm{~m}$ (F3), respectively.

\section{Results and discussions}

DFOS can measure deformation at micro-strain range along a single OF installed in boreholes. The deformation of any strata can be calculated based on strain profile along OF.
Table 1. Deformation of each stratum in G06.

\begin{tabular}{rrlr}
\hline Layer & $\begin{array}{r}\text { Depth } \\
(\mathrm{m})\end{array}$ & Lithology & $\begin{array}{r}\text { Deformation } \\
(\mathrm{mm})\end{array}$ \\
\hline 1 & 2.8 & Silty clay & $\mathrm{NA}$ \\
2 & 18.8 & Clay silt, Silty fine sand & -30.18 \\
3 & 20.0 & Clay silt & -0.61 \\
4 & 23.0 & Silty clay & -1.34 \\
5 & 35.0 & Silty clay & -3.11 \\
6 & 39.8 & Clay silt & -0.51 \\
7 & 56.0 & Fine sand & -0.23 \\
8 & 57.9 & Clay silt & -0.11 \\
9 & 59.6 & Silty clay & 0.05 \\
10 & 63.0 & Clay silt, Silty clay & 0.08 \\
11 & 64.0 & Silty fine sand & 0.10 \\
12 & 69.4 & Silty clay, Clay silt & -0.02 \\
13 & 74.0 & Silty clay & 0.14 \\
14 & 88.1 & Fine sand & -0.70 \\
15 & 90.7 & Clay silt, Silt & -0.18 \\
16 & 97.3 & Silty clay & -0.46 \\
\hline Total & & & -37.07 \\
\hline
\end{tabular}

Note: Positive values in deformation mean soil rebound while negative values mean soil compression. NA $=$ not available.

Each layer deformation was calculated by strain along 5FPC, then the refined soil deformation in the borehole was obtained (Table 1, Fig. 2). The DFOS results showed that the subsidence in the study site reached $37.07 \mathrm{~mm}$ on 30 May 2019 and its subsidence rate is $21.2 \mathrm{~mm} \mathrm{a}^{-1}$. The Layer 2 (L2) cumulative subsidence is $30.18 \mathrm{~mm}$, accounting for $81.41 \%$ of the G06 profile, and the rate is $17.25 \mathrm{~mm} \mathrm{a}^{-1}$. The cumulative subsidence of L3-L5 are 0.61, 1.34, and $0.11 \mathrm{~mm}$, respectively, accounting for $1.65 \%, 3.61 \%$, and $8.39 \%$, respectively. The L2-L5 were always compressing, which were the dominant contributed strata of land subsidence.

The results of a group of extensometers consist of subsidence of four extensometers (F0-F3), as shown in Fig. $1 b$. The soil deformation is calculated by the difference between two extensometers, and the results presented that the total compression of soil between F0-F3 is $139.2 \mathrm{~mm}$ from July 2011 to July 2017 . The compression of three layers is $131.3,6.43$, and $1.47 \mathrm{~mm}$, respectively. The extensometers results showed that $\mathrm{F} 0-\mathrm{F} 1$ accounts for $94.32 \%$ of the total 95.5 m-deep profile (F0-F3) while the soil deformation monitored by DFOS at the same depth accounts for $93.83 \%$ from 2017 to 2019 (Fig. 2a). The results of two methods are less than $1 \%$ when monitoring the strata at the same depths. The continuous deformation is significant for evaluating every layer contribution to land subsidence, which is more detailed than one of extensometers.

As shown in Fig. 2b, Tianjin suffered from severe land subsidence before 1987 and the subsidence rate decreased to $\sim 20 \mathrm{~mm} \mathrm{a}^{-1}$ under government control. The land subsi- 
(a)

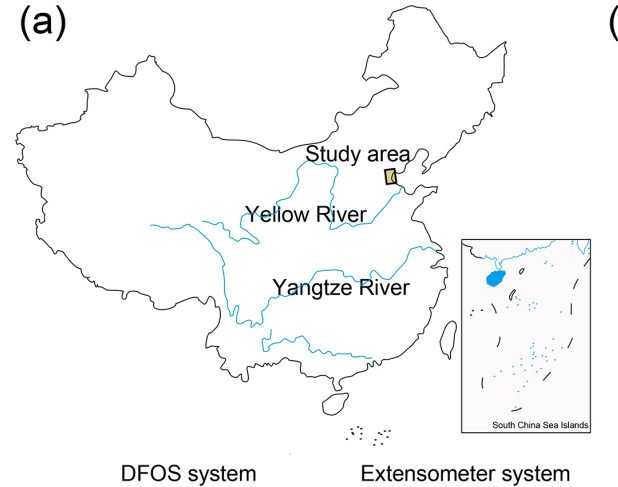

(b)

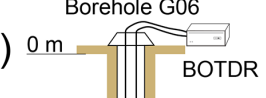

$0 \mathrm{~m}=$ BOTDR

Extensometer system
Borehole G02 group

$3 \mathrm{~m}$

( )

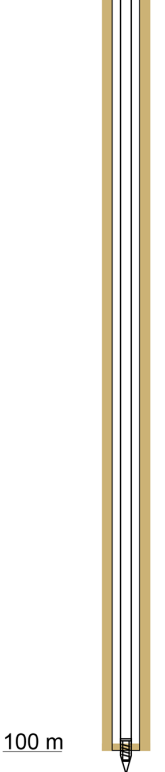

(c)

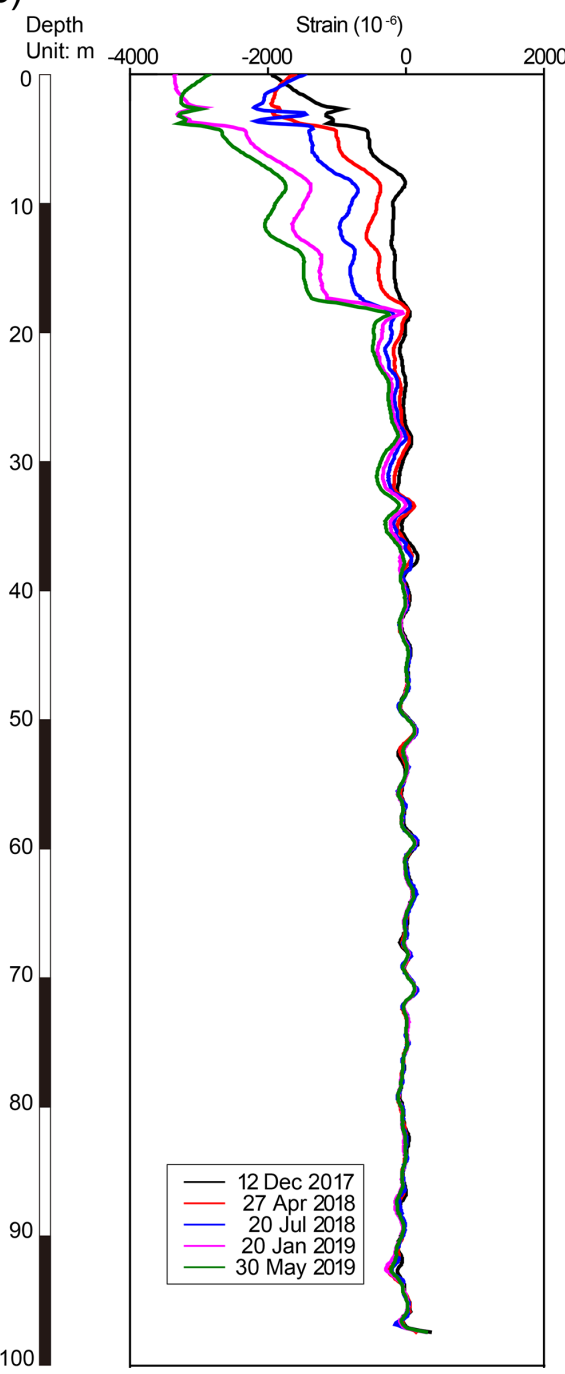

Figure 1. Location of G06 borehole and the DFOS system of land subsidence. (a) Location of study area, China. (b) DFOS system and extensometers system. (c) Strain measured along 5-FPC.

(a)

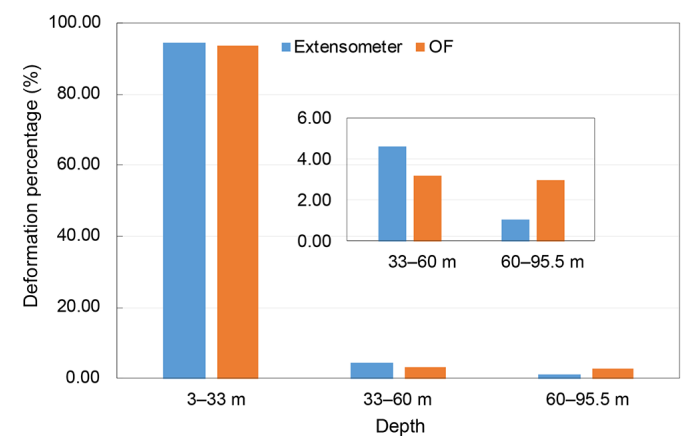

(b)

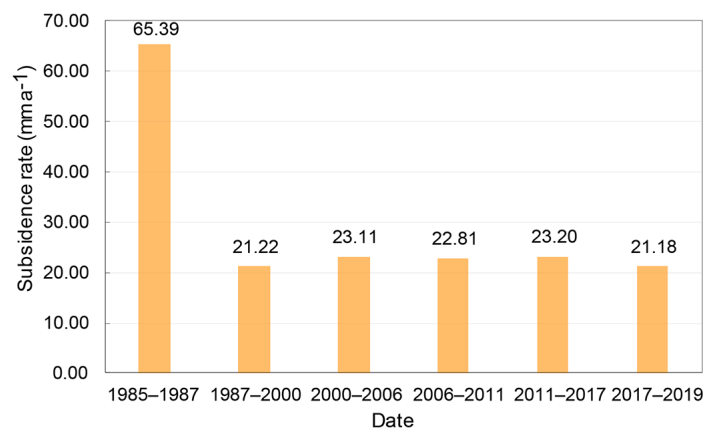

Figure 2. Land subsidence in Tianjin. (a) Comparison between optical fiber (OF) and extensometer at different depths. (b) Historical land subsidence in Tianjin from 1985 to 2019 (R. Hu et al., 2002; B. Hu et al., 2009; Yang et al., 2019). 
dence rate measured by DFOS is $21.2 \mathrm{~mm} \mathrm{a}^{-1}$ while the result of extensometers is $23.2 \mathrm{~mm} / \mathrm{a}$, so the results obtained by two technologies are reasonable. Furtherly, these contributions of strata compression to subsidence calculated by above two methods are consistent in Fig. 2a.

In addition to great performance in quantitative assessment of a $100 \mathrm{~m}$ depth borehole, more research should be investigated, such as accuracy of DFOS at deeper depths, OF types and backfill materials for different areas, wireless monitoring system development, etc.

\section{Conclusions}

This paper aims to propose a robust and effective monitoring technique for land subsidence in coastal areas. In the case study, the DFOS monitoring system was established into a borehole in Tianjin, China, and a comparison of results measured by DFOS and extensometers was presented. The deformation of each soil layer was obtained, and the total subsidence rate is $21.6 \mathrm{~mm} \mathrm{a}^{-1}$ from October 2017 to May 2019, while the dominant strata that contributed to land subsidence was localized at L2-L5. In agreement with extensometers results, DFOS can finely monitored the development of land subsidence and precisely localized the compressed strata in Tianjin.

Data availability. Data are available upon request by contacting the corresponding author.

Author contributions. SPL performed the concept of the investigation and completed the manuscript. BS and KG proposed the method, discussed the field investigation results, reviewed and commented on the manuscript. CCZ helped to analyse the data and review the manuscript. JLY, SZ, and PY provided assistance for field data collection and analyses.

Competing interests. The authors declare that they have no conflict of interest.

Special issue statement. This article is part of the special issue "TISOLS: the Tenth International Symposium On Land Subsidence - living with subsidence". It is a result of the Tenth International Symposium on Land Subsidence, Delft, the Netherlands, 17-21 May 2021.

Acknowledgements. We thank Chang-Yu Zhang and JianHui He from Nanjing University, Guang-Qing Wei and QiuSheng Zhang from Suzhou NanZee Sensing Ltd who were involved in the land subsidence monitoring in Tianjin for their field and technical assistance.
Financial support. This research has been supported by the National Natural Science Foundation of China (grant nos. 41427801, 41230636, and 41977217), the Key Project of Nanjing University Technology Innovation Fund (grant no. SC-2019-101), the Postgraduate Research \& Practice Innovation Program of Jiangsu Province (grant no. KYCX19_0048), and the China Scholarship Council (grant no. 201906190153).

\section{References}

Amelung, F., Galloway, D. L., Bell, J. W., Zebker, H. A., and Laczniak, R. J.: Sensing the ups and downs of Las Vegas: InSAR reveals structural control of land subsidence and aquifer-system deformation, Geology, 27, 483-486, https://doi.org/10.1130/00917613(1999)027<0483:STUADO>2.3.CO;2, 1999.

Baldi, P., Casula, G., Cenni, N., Loddo, F., and Pesci, A.: GPS-based monitoring of land subsidence in the Po Plain (Northern Italy), Earth Planet. Sc. Lett., 288, 204-212, https://doi.org/10.1016/j.epsl.2009.09.023, 2009.

Erkens, G., Bucx, T., Dam, R., de Lange, G., and Lambert, J.: Sinking coastal cities, Proc. Int. Assoc. Hydrol. Sci., 372, 189-198, https://doi.org/10.5194/piahs-372-189-2015, 2015.

Galloway, D. L., Erkens, G., Kuniansky, E. L., and Rowland, J. C.: Preface: Land subsidence processes, Hydrogeol. J., 24, 547-550, https://doi.org/10.1007/s10040-016-1386-y, 2016.

Gu, K., Shi, B., Liu, C., Jiang, H., Li, T., and Wu, $\mathrm{J}$ : Investigation of land subsidence with the combination of distributed fiber optic sensing techniques and microstructure analysis of soils, Eng. Geol., 240, 34-47, https://doi.org/10.1016/j.enggeo.2018.04.004, 2018.

Hu, B., Zhou, J., Wang, J., Chen, Z., Wang, D., and Xu, S.: Risk assessment of land subsidence at Tianjin coastal area in China, Environ. Earth Sci., 59, 269-276, https://doi.org/10.1007/s12665009-0024-6, 2009.

Hu, R., Wang, S., Lee, C., and Li, M.: Characteristics and trends of land subsidence in Tanggu, Tianjin, China, Bull. Eng. Geol. Environ., 61, 213-225, https://doi.org/10.1007/s100640100132, 2002.

Ohno, H., Naruse, H., Kihara, M., and Shimada, A.: Industrial Applications of the BOTDR Optical Fiber Strain Sensor, Opt. Fiber Technol., 7, 45-64, https://doi.org/10.1006/ofte.2000.0344, 2001.

Shearer, T. R.: A numerical model to calculate land subsidence, applied at Hangu in China, Eng. Geol., 49, 85-93, https://doi.org/10.1016/s0013-7952(97)00074-4, 1998.

Wu, J., Jiang, H., Su, J., Shi, B., Jiang, Y., and Gu, K.: Application of distributed fiber optic sensing technique in land subsidence monitoring, J. Civ. Struct. Health Monit., 5, 587-597, https://doi.org/10.1007/s13349-015-0133-8, 2015.

Xue, Y.-Q., Zhang, Y., Ye, S.-J., Wu, J.-C., and Li, Q.-F.: Land subsidence in China, Environ. Geol., 48, 713-720, https://doi.org/10.1007/s00254-005-0010-6, 2005.

Yang, J., Cao, G., Han, D., Yuan, H., Hu, Y., Shi, P., and Chen, Y.: Deformation of the aquifer system under groundwater level fluctuations and its implication for land subsidence control in the Tianjin coastal region, Environ. Monit. Assess., 191, 162, https://doi.org/10.1007/s10661-019-7296-4, 2019. 
Yi, L., Zhang, F., Xu, H., Chen, S. J., Wang, W., and Yu, Q.: Land subsidence in Tianjin, China, Environ. Earth Sci., 62, 11511161, https://doi.org/10.1007/s12665-010-0604-5, 2011.
Zhang, C.-C., Shi, B., Gu, K., Liu, S.-P., Wu, J.-H., Zhang, S., Zhang, L., Jiang, H.-T., and Wei, G.-Q.: Vertically Distributed Sensing of Deformation Using Fiber Optic Sensing, Geophys. Res. Lett., 45, 11732-11741, https://doi.org/10.1029/2018g1080428, 2018. 